\title{
KCNE3 T4A as the Genetic Basis of Brugada-Pattern Electrocardiogram
}

\author{
Tadashi Nakajima, MD, PhD; Jie Wu, PhD; Yoshiaki Kaneko, MD, PhD; \\ Takashi Ashihara, MD, PhD; Seiko Ohno, MD, PhD; Tadanobu Irie, MD; \\ Wei-Guang Ding, MD, PhD; Hiroshi Matsuura, MD, PhD; \\ Masahiko Kurabayashi, MD, PhD; Minoru Horie, MD, PhD
}

\begin{abstract}
Background: Brugada syndrome (BrS) is genetically heterogeneous. In Japanese BrS patients, except for SCN5A and $K C N E 5$, mutations in the responsible genes have not yet been identified, and therefore the genetic heterogeneity remains poorly elucidated.

Methods and Results: Forty consecutive patients with Brugada-pattern electrocardiogram (ECG) underwent comprehensive genetic analysis of BrS-causing genes including SCN5A, SCN1B, SCN3B, CACNA1C, CACNB2, KCNE3 and KCNE5. Besides identifying 8 SCN5A mutations in the present cohort, a KCNE3 T4A mutation was found in a 55-year-old male patient who had experienced several episodes of syncope. A head-up tilt test during passive tilt provoked both hypotension and bradycardia, followed by syncope. He was therefore diagnosed with neurally mediated syncope (NMS). To characterize the functional consequence of the mutant, electrophysiological experiments using whole-cell patch-clamp methods and computer simulations using human right ventricular wall model were carried out. It was found that KCNE3 T4A increased lto recapitulated by heterologously coexpressing Kv4.3+KChIP2b + KCNE3-wild type or KCNE3-T4A in CHO cells.
\end{abstract}

Conclusions: A KCNE3 T4A mutation was identified in a Japanese patient presenting Brugada-pattern ECG and NMS. Its functional consequence was the gain of function of lto, which could underlie the pathogenesis of Brugadapattern ECG. The data provide novel insights into the genetic basis of Japanese BrS. (Circ J 2012; 76: 27632772)

Key Words: Brugada syndrome; Ito; KCNE3; Mutation; Neurally mediated syncope

B rugada syndrome $(\mathrm{BrS})$ is a hereditable disorder characterized by ST-segment elevations in the right precordial electrocardiogram (ECG) leads, associated with a high incidence of syncope or sudden death due to ventricular tachyarrhythmias, which mostly affects men. BrS is genetically heterogeneous, and has been linked to mutations in genes that perturb cardiac ion currents ( $\mathrm{INa}_{\mathrm{Na}} \mathrm{ICa}_{\mathrm{Ca}}$ IK-ATP and $\mathrm{I}_{\mathrm{t}}$ ) contributing to the early phase of action potential (AP). ${ }^{1-12}$ Among the BrScausing genes, mutations in SCN5A (encoding the pore-forming $\alpha$-subunit of the cardiac voltage-gated sodium channel) have accounted for the major form of $\mathrm{BrS}$ in approximately $20 \%$ of cases, and other gene mutations for approximately $10 \%,{ }^{1-12}$ thus around $70 \%$ of $\mathrm{BrS}$ cases remain to be geneti- cally elucidated.

The transient outward potassium current ( $\left.\mathrm{I}_{\mathrm{to}}\right)$ in the heart functions mainly during the early phase of AP because it activates and inactivates rapidly on membrane depolarization. Predominant expression of Ito in ventricular epimyocardium compared to endomyocardium, especially in the right ventricle, contributes to the rapid repolarization and the initial plateau formation of the AP (AP notch). ${ }^{13-15}$ Experimental studies suggested that the gain of function of Ito leads to augmentation of the AP notch in epimyocardium but not in endomyocardium, thus resulting in the enhancement of transmural voltage gradient during the ventricular repolarization, which is thought to be responsible for the ST-segment elevation in the right pre-

Received April 25, 2012; revised manuscript received July 26, 2012; accepted August 7, 2012; released online September 13, 2012 Time for primary review: 28 days

Department of Medicine and Biological Science, Gunma University Graduate School of Medicine, Maebashi (T.N., Y.K., T.I., M.K.); Department of Cardiovascular and Respiratory Medicine (J.W., T.A., S.O., M.H.), Department of Physiology (W.-G.D., H.M.), Shiga University of Medical Science, Otsu, Japan; and Department of Pharmacology, Medical School of Xi'an Jiaotong University, Xi'an, Shaanxi (J.W.), China

The first two authors contributed equally to this work (T.N., J.W.).

Mailing address: Minoru Horie, MD, PhD, Department of Cardiovascular and Respiratory Medicine, Shiga University of Medical Science,

Seta Tsukinowa-cho, Otsu 520-2192, Japan. E-mail: horie@belle.shiga-med.ac.jp

ISSN-1346-9843 doi:10.1253/circj.CJ-12-0551

All rights are reserved to the Japanese Circulation Society. For permissions, please e-mail: cj@j-circ.or.jp 
cordial ECG leads (Brugada-pattern ECG) in BrS. ${ }^{14}$ Further augmentation of the AP notch in epimyocardium causes the loss of AP plateau phase (dome), which consequently leads to arrhythmogenesis in $\mathrm{BrS}$ defined as phase 2 reentry. ${ }^{14} \mathrm{I}$ to in human ventricle is thought to be consist of $\alpha$-subunit Kv4.3 (encoded by $K C N D 3$ ) and $\beta$-subunits including $\mathrm{Kv}$ channel interacting protein (KChIP), KCNE, diaminopeptidyl transferase-like protein (DPP) and $\mathrm{Kv} \beta$ families. ${ }^{16-24}$ Accordingly, mutations in the related genes that increase Ito may underlie the pathogenesis of $\mathrm{BrS}$.

$K C N E 3,1$ member of the $K C N E$ gene family ( $K C N E 1-5)$, modulates the function of Kv4.3 as an inhibitory $\beta$-subunit. ${ }^{19,20}$ Recently, Delpón et al identified a KCNE3 R99H mutation in $1 \mathrm{BrS}$ family. ${ }^{6}$ Functional analysis using the heterologous expression system that recapitulates Ito by coexpression of $\mathrm{Kv} 4.3$ with KCNE3-wild type (WT)/R99H showed that KCNE3 R99H causes a gain of function of Ito by a dominant-positive effect, thus precipitating the development of BrS. ${ }^{6}$ Moreover, mutations in Kv4.3 and KCNE5, which also functions as an inhibitory $\beta$-subunit of $\mathrm{I}_{\mathrm{to}}$, were identified in BrS patients. ${ }^{9,10}$ Functional analysis of these mutations showed that they increase Ito. ${ }^{9,10}$ Therefore, it was established that the gain of function of Ito by mutations in genes that encode Ito could be one of the causes of $\mathrm{BrS}$.

We have previously reported the identification of 8 mutations in SCN5A among 30 consecutive Japanese patients with Brugada-pattern ECG. ${ }^{25}$ Considering that the genetic heterogeneity of BrS is poorly elucidated in Japan, ${ }^{10,26,27}$ we further conducted genetic screening of BrS-causing genes among the 30 consecutive patients and another 10 new patients with Brugada-pattern ECG, and identified a KCNE3 T4A mutation in a patient presenting with neurally mediated syncope (NMS). In the present study, we describe the clinical phenotype of the KCNE3 T4A carrier, and characterize the functional consequence of the Ito recapitulated by heterologously coexpressing Kv4.3 + KChIP2b + KCNE3-T4A in CHO cells. Furthermore, we performed computer simulations based on the Ito obtained in electrophysiological recordings, and showed that KCNE3T4A recapitulated the ECG phenotype.

\section{Methods}

\section{Subjects}

The present subjects were 40 consecutive patients (probands; 35 male, $47 \pm 16$ years of age) with Brugada-pattern ECG who were referred to Gunma University Hospital between April 2002 and September 2010. All patients, except for patient 27, presented with coved-type ST-elevation in the right precordial ECG leads with or without provocation of $\mathrm{Na}$ channel blocker (pilsicainide: $1 \mathrm{mg} / \mathrm{kg}$, or procainamide $5 \mathrm{mg} / \mathrm{kg}$ ), although it is still under debate whether patients with drug-induced Brugadapattern ECG have poor prognosis. ${ }^{28,29}$ Echocardiography and conventional left catheterization, if performed, indicated no structural heart disease in all the patients. Thirty-two patients underwent electrophysiological assessment. Up to 3 extra stimuli (minimum coupling interval: $180 \mathrm{~ms}$ ) were delivered from 2 ventricular sites (right ventricular apex and right ventricular outflow tract). A head-up tilt (HUT) test was performed using the same protocol as described previously. ${ }^{30}$ Clinical features of the subjects are listed in Table $\mathbf{1 .}$

\section{Genetic Analysis}

After obtaining appropriate approval from the institution review board and written informed consent from the patient, genomic DNA was extracted from peripheral blood lymphocytes using the standard protocol of the QIAamp DNA Blood Midi Kit (QIAGEN, Hilden, Germany). All coding exons of $S C N 5 A$, $S C N 1 B, K C N E 3, S C N 3 B$ and KCNE5, and their splice sites were amplified on polymerase chain reaction (PCR) using primers flanking the intronic sequences as reported previously. ${ }^{1,5-7,25,31}$ The PCR products were purified and directly sequenced using an ABI PRISM 3130 Genetic Analyzer (Applied Biosystems, Foster City, CA, USA). Regarding patient 18, CACNA1C and CACNB2 were also analyzed. ${ }^{4}$ The mutation was analyzed twice on independent PCR amplification and sequencing. KCNE3 T4A was not identified in 528 control alleles.

\section{Heterologous Expression of hKv4.3 and $\beta$-Subunits in CHO Cells}

Full-length cDNA fragment of WT KCNE3 in pCR3.1 vector was subcloned into pIRES-CD8 vector that is useful in cell selection. The KCNE3 mutant (T4A) was constructed using a Quick Change II XL site-directed mutagenesis kit according to the manufacturer's instructions (Stratagene, La Jolla, CA, USA) and subcloned to the same vector. The KCNE3 mutant was fully sequenced (ABI PRISM 3130 Genetic analyzer) to ensure fidelity. Full-length cDNA encoding the short isoform of human Kv4.3 (hKv4.3) subcloned into the pIRES-GFP (Clontech, Palo Alto, CA, USA) expression vector was kindly provided by Dr GF Tomaselli (Johns Hopkins University). Full-length cDNA encoding Kv channel-interacting protein $2 \mathrm{~b}$ (KChIP2b) subcloned into the PCMV-IRS expression vector was a kind gift from Dr GN Tseng (Virginia Commonwealth University). Kv4.3 was transiently transfected into $\mathrm{CHO}$ cells together with KChIP2b and KCNE3-WT (or T4A) cDNA at equimolar ratio $(\mathrm{Kv} 4.3,1.0 \mu \mathrm{g}$; KChIP2b, $1.0 \mu \mathrm{g}$; KCNE3, $1.0 \mu \mathrm{g}$ ) using Lipofectamine (Invitrogen Life Technologies, Carlsbad, CA, USA) according to the manufacturer's instructions. In a subset of experiments, $0.5 \mu \mathrm{g}$ KCNE3-WT and $0.5 \mu \mathrm{g}$ $\mathrm{KCNE} 3-\mathrm{T} 4 \mathrm{~A}$ were co-transfected into cells with $1.0 \mu \mathrm{g} \mathrm{Kv} 4.3$ and $1.0 \mu \mathrm{g} \mathrm{KChIP} 2 \mathrm{~b}$. The transfected cells were then cultured in Ham's F-12 medium (Nakalai Tesque, Kyoto, Japan) as described previously. ${ }^{24}$

\section{Electrophysiologic Recording and Data Analysis}

After $48 \mathrm{~h}$ of transfection, a coverslip with cells was transferred to a $0.5-\mathrm{ml}$ bath chamber at $25^{\circ} \mathrm{C}$ on an inverted microscope stage and perfused at $1-2 \mathrm{ml} / \mathrm{min}$ with extracellular solution containing the following (in mmol/L): $140 \mathrm{NaCl}, 5.4 \mathrm{KCl}, 1.8$ $\mathrm{CaCl}_{2}, 0.5 \mathrm{MgCl}_{2}, 0.33 \mathrm{NaH}_{2} \mathrm{PO}_{4}, 5.5$ glucose, and 5.0 HEPES; $\mathrm{pH} 7.4$ with $\mathrm{NaOH}$. Cells that emitted green fluorescence were chosen for patch-clamp experiments. If coexpressed with KCNE3 (or its mutant), the cells were incubated with polystyrene microbeads precoated with anti-CD8 antibody (Dynabeads M450, Dynal, Norway) for $15 \mathrm{~min}$. In these cases, cells that emitted green fluorescence and had attached beads were chosen for electrophysiologic recording. Whole-cell membrane currents were recorded with an EPC-8 patch-clamp amplifier (HEKA, Lambrecht, Germany), and data were low-pass filtered at $1 \mathrm{kHz}$, acquired at $5 \mathrm{kHz}$ through an LIH-1600 analog-todigital converter (HEKA), and stored on hard disk using PulseFit software (HEKA). Patch pipettes had a resistance of 2.5$5.0 \mathrm{~mol} / \mathrm{L} \Omega$ when filled with the following pipette solution (in $\mathrm{mmol} / \mathrm{L}$ ): 70.0 potassium aspartate, $50.0 \mathrm{KCl}, 10.0 \mathrm{KH}_{2} \mathrm{PO}_{4}$, 1.0 MgSO 4, 3.0 Na2-ATP (Sigma, Japan, Tokyo), 0.1 Li2-GTP (Roche Diagnostics, Mannheim, Germany), 5.0 EGTA, and 5.0 HEPES (pH 7.2).

Whole cell currents were elicited in a series of depolarizing voltage steps from a holding potential of $-80 \mathrm{mV}$. The time 


\begin{tabular}{|c|c|c|c|c|c|c|c|c|c|c|c|c|}
\hline $\begin{array}{c}\text { Patient } \\
\text { no. }\end{array}$ & Sex & $\begin{array}{c}\text { Age } \\
\text { (years) }\end{array}$ & ECG & Symptom & $\mathbf{F H}$ & EPS & ICD & SCN5A & SCN1B & $S C N 3 B$ & KCNE3 & KCNE5 \\
\hline 1 & $M$ & 49 & Coved $(P)$ & Sy & No & VF & Yes & c. $393-1 \mathrm{c}>\mathrm{t}^{\star *}$ & & & & \\
\hline 2 & $\mathrm{~F}$ & 58 & Coved & Asy & No & N/A & No & $\mathrm{R} 1193 \mathrm{Q}$ & & & & \\
\hline 3 & M & 36 & Coved (P) & Asy & No & VF & No & $\mathrm{A} 586 \mathrm{~T}^{\star \star}$ & & & & \\
\hline 4 & $M$ & 29 & Coved $(P)$ & Sy & No & VF & Yes & & $\begin{array}{l}\text { L210P, S248R, } \\
\text { R250T }\end{array}$ & & & \\
\hline 5 & $M$ & 56 & Coved & CPA & No & VF & Yes & & L210P & & & \\
\hline 6 & $M$ & 30 & Coved & CPA & No & VF & Yes & & & & & \\
\hline 7 & $M$ & 42 & Coved $(P)$ & Sy & No & No VF & Yes & & & & & \\
\hline 8 & $\mathrm{M}$ & 53 & Coved $(P)$ & CPA & No & No VF & Yes & & R187H, L210P & & & \\
\hline 9 & $M$ & 45 & Coved & CPA & No & VF & Yes & P1090L & $\begin{array}{l}\text { L210P, S248R, } \\
\text { R250T }\end{array}$ & & & \\
\hline 10 & $M$ & 47 & Coved $(P)$ & CPA & No & VF & Yes & & L210P & & & \\
\hline 11 & $M$ & 39 & Coved $(\mathrm{P})$ & Asy & No & NSVT & No & & L210P & & & \\
\hline 12 & $\mathrm{M}$ & 32 & Coved & Asy & Yes & $\mathrm{N} / \mathrm{A}$ & Yes & & $\begin{array}{l}\text { L210P, S248R, } \\
\text { R250T }\end{array}$ & & & \\
\hline 13 & $M$ & 42 & $\begin{array}{l}\text { Coved } \\
\text { (Pro) }\end{array}$ & Sy & No & VF & Yes & $\begin{array}{l}\text { P1090L, } \\
\text { R1232W }\end{array}$ & & & & \\
\hline 14 & $M$ & 59 & Coved $(P)$ & Asy & No & No VF & No & c. $4437+5 \mathrm{~g}>\mathrm{a}$ & & & & \\
\hline 15 & $M$ & 64 & Coved & Asy & No & $\mathrm{N} / \mathrm{A}$ & No & & $\begin{array}{c}\mathrm{L}^{\mathrm{L} 210 \mathrm{P}^{*}, \mathrm{~S} 248 \mathrm{R}^{*}}, \\
\mathrm{R}^{2} 50 \mathrm{~T}^{*}\end{array}$ & & & \\
\hline 16 & $\mathrm{M}$ & 39 & Coved $(P)$ & Asy & No & NSVT & No & & & & & \\
\hline 17 & $M$ & 61 & Coved $(P)$ & Asy & Yes & NSVT & No & $\mathrm{R} 689 \mathrm{H}^{* *}$ & & & & \\
\hline 18 & $M$ & 55 & Coved $(P)$ & Sy & No & NSVT & No & & & & $\mathrm{T} 4 \mathrm{~A}^{* *}$ & \\
\hline 19 & $M$ & 37 & Coved $(P)$ & Sy & Yes & VF & Yes & & $\begin{array}{l}\text { L210P, S248R, } \\
\text { R250T }\end{array}$ & & & \\
\hline 20 & $M$ & 49 & Coved $(\mathrm{P})$ & Asy & No & No VF & No & $\begin{array}{l}\text { H558R*, } \\
\text { S1553R }\end{array}$ & & & & \\
\hline 21 & $\mathrm{~F}$ & 38 & Coved $(\mathrm{P})$ & Asy & No & $\mathrm{N} / \mathrm{A}$ & No & & & & & \\
\hline 22 & $M$ & 64 & Coved $(\mathrm{P})$ & Asy & Yes & VF & Yes & $\begin{array}{l}\text { H558R, } \\
\text { R1193Q }\end{array}$ & $\begin{array}{l}\text { L210P, S248R, } \\
\text { R250T }\end{array}$ & & & \\
\hline 23 & $M$ & 71 & Coved $(\mathrm{P})$ & CPA & No & No VF & Yes & P1090L & 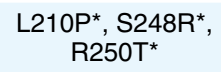 & & & \\
\hline 24 & $M$ & 44 & Coved $(P)$ & Sy & Yes & VF & Yes & $\mathrm{E}_{1784 \mathrm{~K}^{* *}}$ & & & & \\
\hline 25 & $M$ & 56 & Coved (P) & Sy & No & VF & Yes & & $\begin{array}{l}\text { L210P, S248R, } \\
\text { R250T }\end{array}$ & & & \\
\hline 26 & $M$ & 15 & Coved & Sy & No & $\mathrm{N} / \mathrm{A}$ & No & & $\begin{array}{c}\text { L210P* }^{*} \text { S248R, } \\
\text { R250T }\end{array}$ & & & \\
\hline 27 & $M$ & 25 & $\begin{array}{l}\text { Saddle- } \\
\text { back }\end{array}$ & Sy & Yes & No VF & Yes & V1951M** & & & & \\
\hline 28 & $\mathrm{~F}$ & 67 & Coved $(P)$ & Asy & No & $\mathrm{N} / \mathrm{A}$ & No & & & & & \\
\hline 29 & $\mathrm{~F}$ & 28 & Coved & Asy & No & $\mathrm{N} / \mathrm{A}$ & No & Q1706 $\mathrm{H}^{* *}$ & & & & \\
\hline 30 & $M$ & 38 & Coved & Sy & No & NSVT & No & & & & & \\
\hline 31 & $M$ & 30 & Coved $(P)$ & Asy & No & No VF & No & & & & & \\
\hline 32 & $M$ & 63 & Coved $(P)$ & Asy & No & NSVT & No & & $\begin{array}{l}\text { L210P, S248R, } \\
\text { R250T }\end{array}$ & & & \\
\hline 33 & $M$ & 43 & Coved & Asy & No & VF & No & & & & & \\
\hline 34 & $\mathrm{M}$ & 57 & Coved & Asy & No & No VF & No & & $\begin{array}{l}\text { L210P, S248R, } \\
\text { R250T }\end{array}$ & & & \\
\hline 35 & $M$ & 40 & Coved $(P)$ & Sy & No & VF & Yes & & $\begin{array}{l}\text { L210P, S248R, } \\
\text { R250T }\end{array}$ & & & \\
\hline 36 & $M$ & 66 & Coved $(P)$ & Sy & No & VF & Yes & & L210P & & & \\
\hline 37 & $\mathrm{M}$ & 72 & Coved $(P)$ & Asy & No & VF & No & & $\begin{array}{l}\text { L210P, S248R, } \\
\text { R250T }\end{array}$ & & & \\
\hline 38 & $M$ & 33 & Coved & Asy & No & NSVT & No & & & & & \\
\hline 39 & $M$ & 77 & Coved & Asy & No & VF & No & & $\begin{array}{l}\text { L210P, S248R, } \\
\text { R250T }\end{array}$ & & & \\
\hline 40 & $\mathrm{~F}$ & 15 & Coved $(\mathrm{P})$ & CPA & No & $\mathrm{N} / \mathrm{A}$ & Yes & $\mathrm{A} 735 \mathrm{E}^{\star \star}$ & & & & \\
\hline
\end{tabular}

Mutations and non-synonymous variants are listed. *Homozygous; **mutations.

Asy, asymptomatic; CPA, cardiopulmonary arrest; ECG, electrocardiogram; EPS, up to 3 extrastimuli from right ventricular apex and right ventricular outflow tract; FH, family history of sudden death under age 45; N/A, not accessed; NSVT, non-sustained ventricular tachycardia; $\mathrm{P}$, pilsicainide provocation; Pro, procainamide provocation; Sy, syncope; VF, ventricular fibrillation. 

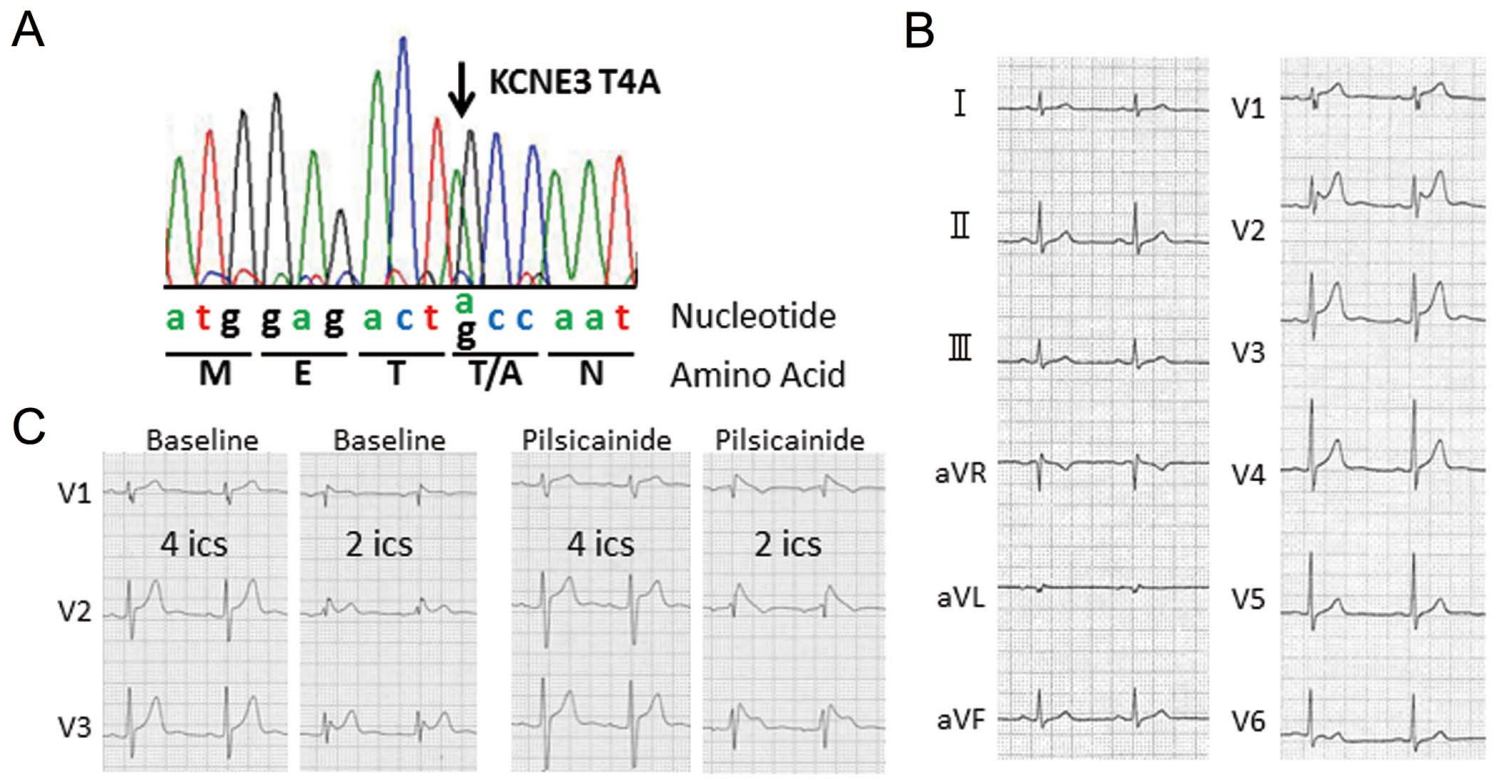

Figure 1. (A) Direct sequencing of the KCNE3 gene in the index patient. Nucleotide and amino acid substitutions are indicated below. (B) Twelve-lead ECG recorded 2 months before admission. (C) $V_{1-3}$ lead electrocardiogram before (baseline) and after pilsicainide provocation (Pilsicainide). ics, intercostal space.

interval between each voltage pulse was $10 \mathrm{~s}$. The difference between the peak current amplitude and the current at the end of a test pulse was referred to as the transient outward current. To control for cell size variability, currents are expressed as densities $(\mathrm{pA} / \mathrm{pF})$ as described previously. ${ }^{24}$ Steady-state activation curves were obtained by plotting the normalized conductance as a function of peak outward potentials. Steady-state inactivation curves were generated by a standard 2-pulse protocol with a conditioning pulse of $500 \mathrm{~ms}$ and obtained by plotting the normalized current as a function of the test potential. Steady-state inactivation/activation kinetics were fitted to the following Boltzmann equation:

$$
\mathrm{Y}(\mathrm{V})=1 /\left(1+\exp \left[\left(\mathrm{V}_{1 / 2}-\mathrm{V}\right) / \mathrm{k}\right]\right),
$$

where $\mathrm{Y}=$ normalized conductance or current, $\mathrm{V}_{1 / 2}=$ potential for half-maximum inactivation or activation, respectively, and $\mathrm{k}=$ slope factor.

Data relative to inactivation time constants, time to peak, and mean current levels were obtained using current data recorded at $+50 \mathrm{mV}$. Recovery from inactivation was assessed using a standard paired-pulse protocol: a 1-s test pulse to $+50 \mathrm{mV}$ (P1) followed by a variable recovery interval at $-80 \mathrm{mV}$ and then a second test pulse to $+50 \mathrm{mV}(\mathrm{P} 2)$. Both the inactivation time constants and the time constant for recovery from inactivation were determined by fitting the data to a single exponential:

$$
\mathrm{I}(\mathrm{t})(\text { or } \mathrm{P} 2 / \mathrm{P} 1)=\mathrm{A}+\mathrm{B} \exp (-\mathrm{t} / \tau) \text {, }
$$

where $\mathrm{I}(\mathrm{t})=$ current amplitude at time $\mathrm{t}, \mathrm{A}$ and $\mathrm{B}=$ constants, and $\tau=$ inactivation time constant or time constant for recovery from inactivation. For measurement of recovery from inactivation, the plot of $\mathrm{P} 2 / \mathrm{P} 1$ instead of $\mathrm{I}(\mathrm{t})$ was used.

All data are given as mean \pm SEM. Statistical comparisons between 2 groups were analyzed using Student's unpaired ttest. Comparisons among multiple groups were analyzed using analysis of variance followed by Dunnett test. $\mathrm{P}<0.05$ was considered significant.

\section{Computer Simulation}

To confirm the exact role of the KCNE3 T4A mutation, we conducted simulations of paced propagation in a $0.5-\mathrm{cm} 1-\mathrm{D}$ bidomain myocardial model with transverse conductivity, mimicking transmural section of right ventricular wall. Membrane kinetics were represented by the Priebe-Beuckelmann human ventricular model, ${ }^{32}$ of which original Ito was replaced by the Ito with KCNE3-WT or KCNE3-T4A mutation obtained in electrophysiologic recording.

To obtain the transmural gradient in the right ventricular wall, we defined endocardial and epicardial tissues as each of length $0.25 \mathrm{~cm}$, and we set the conductances of the slowly activating component of the delayed rectifier potassium channel (IKs), the inward rectifier potassium channel ( $\left.\mathrm{I}_{\mathrm{K} 1}\right)$, and $\mathrm{I}_{\mathrm{to}}$ in the endocardial layers to $46 \%, 82 \%$, and $29 \%$, respectively, of those in the epicardial layers. Pacing stimuli of $2 \mathrm{~ms}$ and strength twice-diastolic threshold were applied transmembranously to the endocardial end at a cycle length of $1,000 \mathrm{~ms}$. The time and spatial discretization steps were $10 \mu \mathrm{s}$ and $50 \mu \mathrm{m}$, respectively. Other model parameters and the numerical approach have been described elsewhere. ${ }^{33}$

\section{Results}

\section{Genetic Analysis}

We conducted comprehensive genetic analysis of $\mathrm{BrS}$-causing genes including SCN5A, SCN1B, KCNE3, SCN $3 B$ and KCNE5, among 40 consecutive patients with Brugada-pattern ECG. Besides identifying $8 S C N 5 A$ mutations in the present cohort, we also found a T4A mutation in KCNE3 in the patient 18 who had no mutations in the other genes (including CACNAIC and $C A C N B 2$ ) associated with $\mathrm{BrS}$ (Figure 1A; Table 1). 

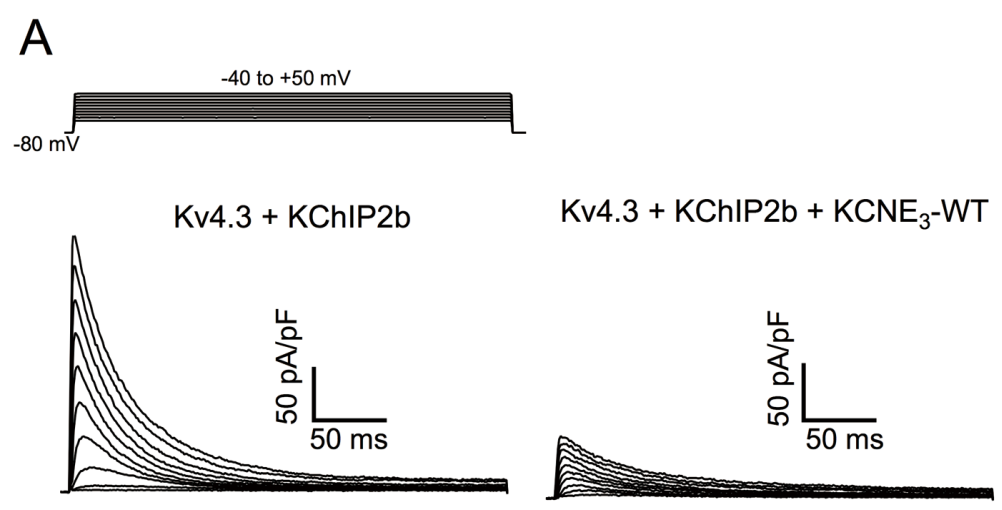

$\mathrm{Kv} 4.3+\mathrm{KChIP} 2 \mathrm{~b}+\mathrm{KCNE}_{3}-\mathrm{T} 4 \mathrm{~A}$
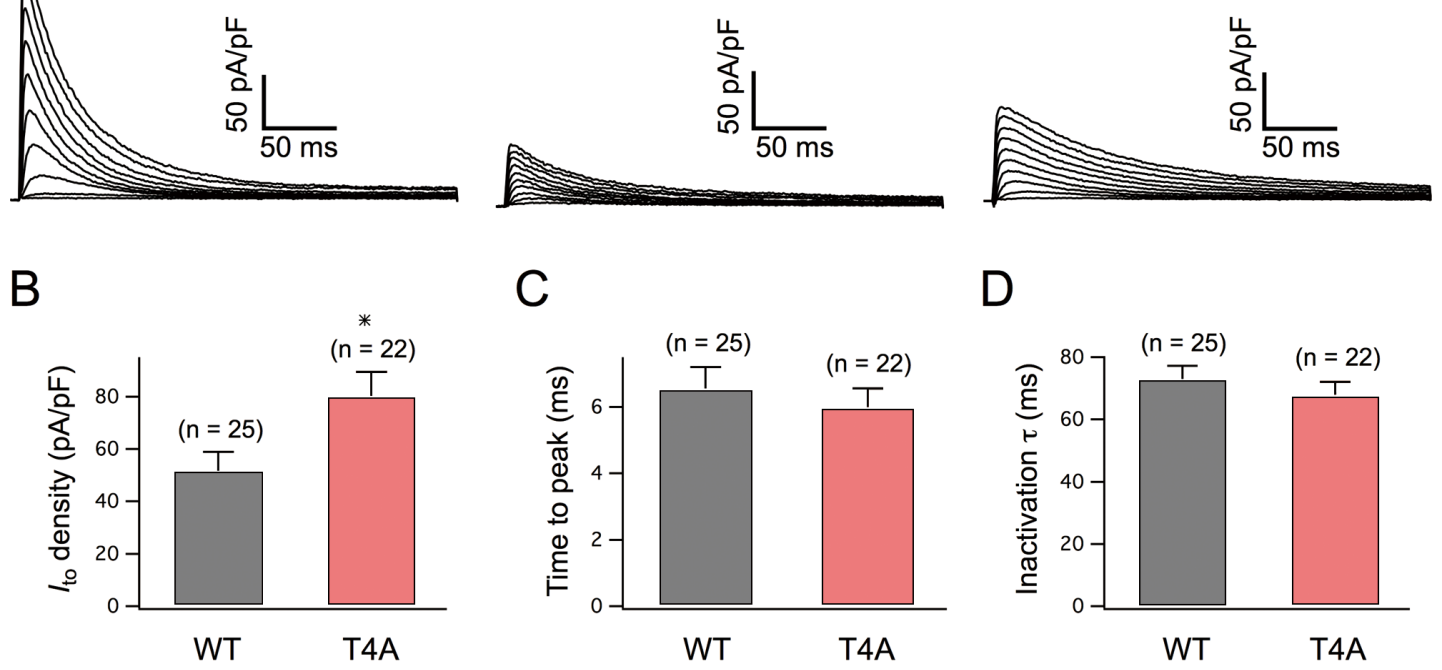

Figure 2. KCNE3-T4A increased lto current reconstituted by coexpression of $1 \mu \mathrm{g} \mathrm{Kv} 4.3+1 \mu \mathrm{g} \mathrm{KChIP2b}+1 \mu \mathrm{g} \mathrm{KCNE3} \mathrm{in} \mathrm{CHO}$ cells. (A) Representative current traces recorded from cells expressing (Left) Kv4.3 + KChIP2b, (Middle) Kv4.3+KChIP2b + KCNE3WT and (Right) Kv4.3+KChIP2b + KCNE3-T4A. Inset, depolarizing test pulses introduced from -80 mV holding potential to potentials ranging from -40 to $+50 \mathrm{mV}$, with $300-\mathrm{ms}$ duration, in $10-\mathrm{mV}$ increments. (B) Peak current density of lto, (C) time to peak of activation course and (D) inactivation time constants recorded at $+50 \mathrm{mV}$. (n), no. of experiments. ${ }^{*} \mathrm{P}<0.05$ vs. WT.

\section{Clinical Presentation}

A 55-year-old man (patient 18) was referred to hospital to examine the cause of syncope. He had experienced several episodes of syncope under specific conditions, such as when sitting at a funeral, and standing up after drinking alcohol, since his $30 \mathrm{~s}$. He had no previous history of illness except for syncopal episodes, and no family history of sudden cardiac death. A physical examination, chest X-ray, and blood test showed no remarkable abnormalities. His 12-lead ECG, recorded 2 months before admission, showed saddle-back-type ST-segment elevation in the right precordial ECG leads (Figure 1B). The QTc interval was $414 \mathrm{~ms}$. A coved-type ST-segment elevation in the right precordial ECG leads at the second intercostal space appeared after provocation with pilsicainide (Figure 1C). Signal-averaged ECG showed no late potentials. Transthoracic echocardiography showed no apparent structural heart disease.

The patient underwent electrophysiological assessment. Up to 3 extrastimuli induced non-sustained polymorphic ventricular tachycardia, but not ventricular fibrillation. An HUT test was performed because syncopal episodes had occurred under specific conditions that could evoke NMS. The HUT test during passive tilt provoked both hypotension and bradycardia, followed by syncope. Therefore, the patient was diagnosed as having NMS. The patient was not prescribed medication or implanted with an implantable cardioverter defibrillator.

\section{KCNE3-T4A Mutation Increased the Current Amplitude of the Kv4.3+KChIP2b+KCNE3 Channel}

Because KCNE3 was shown to co-associate with Kv4.3 in the human heart, and Ito is thought to underlie the development of Brugada phenotype, ${ }^{6,15}$ KCNE3-WT/T4A was coexpressed together with Kv4.3 and KChIP2b, which has been shown to serve as a principal $\beta$-subunit of Ito. ${ }^{18,19,34,35}$ Figure 2A shows representative whole-cell current traces recorded from $\mathrm{CHO}$ cells expressing Kv4.3 + KChIP2b, Kv4.3 + KChIP2b + KCNE3WT and Kv4.3 + KChIP2b + KCNE3-T4A.

Consistent with the previous literature, coexpression of KCNE3-WT dramatically reduced the current amplitude of the Kv4.3 + KChIP2b channel. ${ }^{6,20,24}$ Further analysis of peak current showed that the current density of the coexpression with the KCNE3-T4A mutant was significantly larger than that for KCNE3-WT (Kv4.3 + KChIP2b + KCNE3-WT, 51.7 \pm 7.3 pA/ $\mathrm{pF}, \mathrm{n}=25$ vs. Kv4.3 + KChIP2b + KCNE3-T4A, 80.2 $\pm 9.1 \mathrm{pA} /$ $\mathrm{pF}, \mathrm{n}=22, \mathrm{P}<0.05$; Figure $2 \mathrm{~A}, \mathrm{~B})$. Figure $2 \mathrm{C}$ shows mean time interval from the onset of the pulse to maximum current (time to peak), and Figure 2D shows the time constants $(\tau)$ of inactivation obtained using a single exponential at $+50 \mathrm{mV}$. These data indicate that KCNE3-T4A mutation increased the current amplitude of the Kv $4.3+\mathrm{KChIP} 2 \mathrm{~b}+\mathrm{KCNE} 3$ channel, but did not affect time to peak and the inactivation time course.

\section{Effect of KCNE3-T4A on Activation/inactivation Kinetics of Kv4.3 + KChIP2b + KCNE3 Channels}

To further examine the effect of KCNE3-T4A on gating kinet- 
A

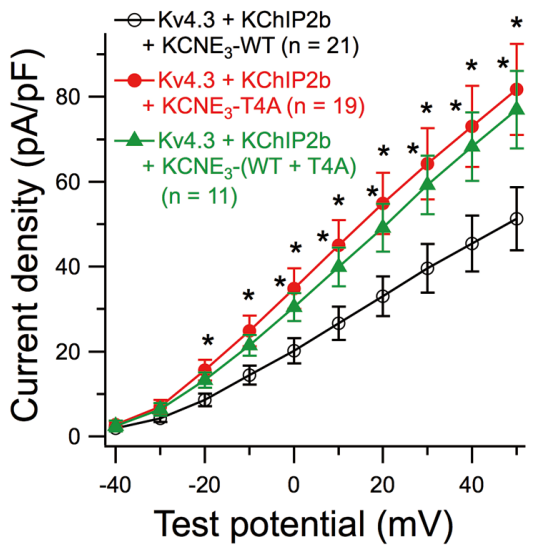

C

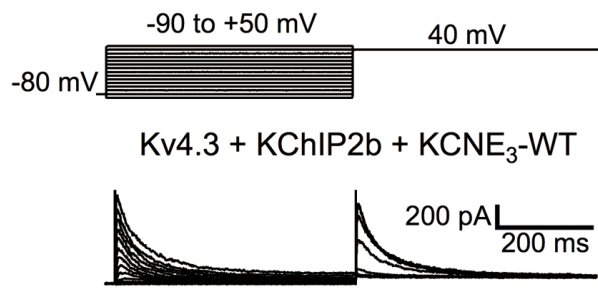

$\mathrm{Kv} 4.3+\mathrm{KChIP} 2 \mathrm{~b}+\mathrm{KCNE}_{3}-\mathrm{T} 4 \mathrm{~A}$

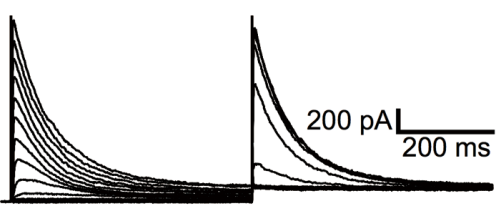

B

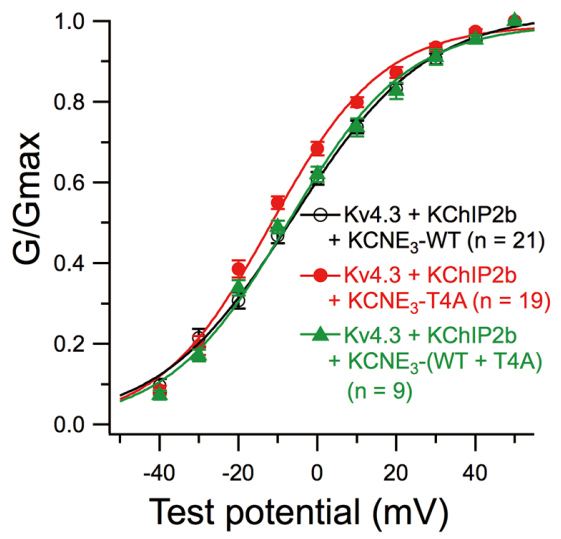

$\mathrm{D}$

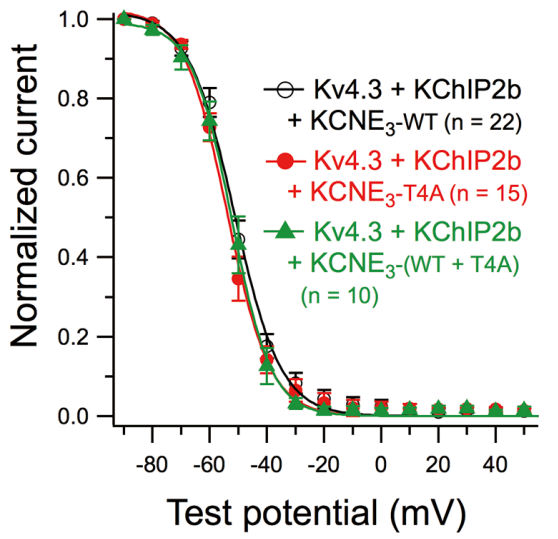

Figure 3. Effect of KCNE3-T4A on activation/inactivation kinetics of Kv4.3+KChIP2b +KCNE3 channels. (A) Current-voltage relationship curves showing peak current densities of the (open circles) Kv4.3 + KChIP2b + KCNE3-WT, (closed circles) KCNE3T4A and (filled triangles) KCNE3-(0.5 $\mu \mathrm{g} \mathrm{WT}+0.5 \mu \mathrm{g} \mathrm{T4A)}$ channels. ${ }^{*} \mathrm{P}<0.05$ vs. Kv4.3 +KChIP2b +KCNE3-WT. (B) Normalized conductance-voltage relationships for peak currents in (A). (C) (Upper) Representative Kv4.3 + KChIP2b + KCNE3-WT, (Lower) Kv4.3 + KChIP2b + KCNE3-T4A current traces induced by 500-ms pre-pulses from $-90 \mathrm{mV}$ to $+50 \mathrm{mV}$ applied from the holding potential $-80 \mathrm{mV}$ in $10-\mathrm{mV}$ steps followed by a second pulse to $+40 \mathrm{mV}$ (fixed) for assessing the inactivation process. (D) Steadystate inactivation curves for the (open circles) Kv4.3 + KChIP2b + KCNE3-WT, (closed circles) KCNE3-T4A, and (filled triangles) KCNE3-(WT + T4A) channels. Peak currents thus measured were normalized by that obtained from the $-90 \mathrm{mV}$ pre-pulse and are plotted against the pre-pulse potentials. Smooth curves were drawn by fitting to the Boltzmann equation.

Table 2. Current Density and Biophysical Kinetics

\begin{tabular}{|c|c|c|c|c|c|c|c|c|}
\hline & \multirow{2}{*}{$\begin{array}{c}\begin{array}{c}\text { Current } \\
\text { density }\end{array} \\
\begin{array}{c}\text { At }+50 \mathrm{mV} \\
(\mathrm{pA} / \mathrm{pF})\end{array}\end{array}$} & \multirow{2}{*}{$\begin{array}{c}\text { Activation } \\
\begin{array}{c}\text { Time to } \\
\text { peak (ms) }\end{array}\end{array}$} & \multicolumn{2}{|c|}{$\begin{array}{l}\text { Steady-state } \\
\text { activation }\end{array}$} & \multicolumn{2}{|c|}{$\begin{array}{l}\text { Steady-state } \\
\text { inactivation }\end{array}$} & \multirow{2}{*}{$\frac{\text { Inactivation }}{\tau(\mathrm{ms})}$} & \multirow{2}{*}{$\begin{array}{c}\begin{array}{c}\text { Recovery } \\
\text { from }\end{array} \\
\text { inactivation }\end{array}$} \\
\hline & & & $\mathrm{V}_{1 / 2}(\mathrm{mV})$ & $k(m V)$ & $\mathrm{V}_{1 / 2}(\mathrm{mV})$ & $k(m V)$ & & \\
\hline $\begin{array}{l}\text { Kv4.3+KChIP2b+ } \\
\text { KCNE3-WT }\end{array}$ & $\begin{array}{c}51.7 \pm 7.3 \\
(n=25)\end{array}$ & $\begin{array}{c}6.6 \pm 0.7 \\
(n=25)\end{array}$ & $\begin{array}{c}-6.5 \pm 2.0 \\
(n=21)\end{array}$ & $\begin{array}{c}17.2 \pm 1.1 \\
(n=21)\end{array}$ & $\begin{array}{c}-52.7 \pm 1.7 \\
(n=22)\end{array}$ & $\begin{array}{c}-9.9 \pm 1.7 \\
(n=22)\end{array}$ & $\begin{array}{c}73.0 \pm 4.2 \\
(n=25)\end{array}$ & $\begin{array}{c}65.7 \pm 10.2 \\
(n=9)\end{array}$ \\
\hline $\begin{array}{l}\text { Kv4.3+KChIP2b+ } \\
\text { KCNE3-T4A }\end{array}$ & $\begin{array}{c}80.2 \pm 9.1^{\dagger} \\
(n=22)\end{array}$ & $\begin{array}{c}6.0 \pm 0.6 \\
(n=22)\end{array}$ & $\begin{array}{c}-11.6 \pm 1.2^{\dagger} \\
(n=19)\end{array}$ & $\begin{array}{c}14.2 \pm 0.8 \\
(n=19)\end{array}$ & $\begin{array}{c}-54.7 \pm 1.6 \\
(n=15)\end{array}$ & $\begin{array}{c}-8.8 \pm 2.1 \\
(n=15)\end{array}$ & $\begin{array}{c}67.1 \pm 4.1 \\
(n=22)\end{array}$ & $\begin{array}{c}66.9 \pm 10.7 \\
(n=9)\end{array}$ \\
\hline $\begin{array}{l}\text { Kv4.3+KChIP2b + } \\
\text { KCNE3-(WT+T4A) }\end{array}$ & $\begin{array}{c}77.7 \pm 8.6^{\dagger} \\
(n=11)\end{array}$ & $\begin{array}{c}6.7 \pm 0.8 \\
(n=11)\end{array}$ & $\begin{array}{c}-7.2 \pm 1.1 \\
(n=10)\end{array}$ & $\begin{array}{c}15.4 \pm 0.8 \\
(n=10)\end{array}$ & $\begin{array}{c}-52.2 \pm 2.0 \\
(n=10)\end{array}$ & $\begin{array}{c}-6.1 \pm 1.1 \\
(n=10)\end{array}$ & $\begin{array}{c}64.3 \pm 9.8 \\
(n=11)\end{array}$ & $\begin{array}{c}72.8 \pm 12.6 \\
(n=6)\end{array}$ \\
\hline
\end{tabular}

${ }^{\dagger} \mathrm{P}<0.05$ vs. Kv4.3+KChIP2b+KCNE3-WT. 


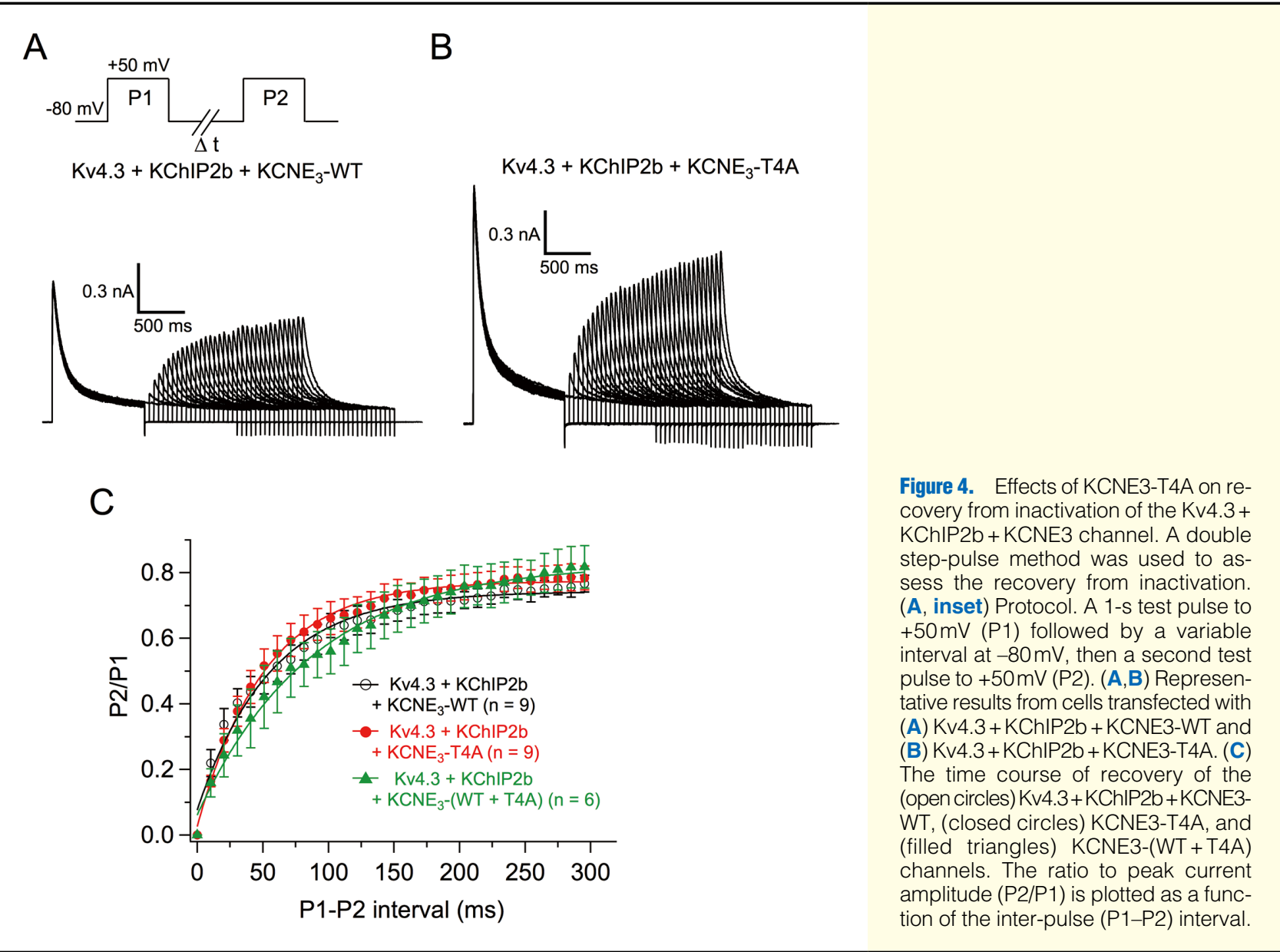

ics of $\mathrm{Kv} 4.3+\mathrm{KChIP} 2 \mathrm{~b}+\mathrm{KCNE} 3$ channel, we assessed the current-voltage (I-V) relationship of the Kv4.3+KChIP $2 b+$ KCNE3-T4A and Kv4.3 + KChIP2b + KCNE3-WT + KCNE3T4A channels. Coexpression of KCNE3-T4A (at -20 to $+50 \mathrm{mV}$ ) or KCNE3-WT $+\mathrm{KCNE} 3-\mathrm{T} 4 \mathrm{~A}($ at 0 to $+50 \mathrm{mV})$ significantly increased peak current densities (Figure 3A; Table 2). Meanwhile, coexpression of KCNE3-T4A, but not KCNE3( T4A $+\mathrm{WT}$ ), also caused a negative shift (approximately $-5 \mathrm{mV}$ ) of voltage dependence of steady-state activation as assessed by plotting the normalized conductance as a function of test potentials (Figure 3B; Table 2).

Figure 3C shows the representative current traces elicited by a double-step pulse method (inset) used to evaluate steadystate inactivation. Peak currents recorded at various levels of pre-pulse (Figure 3C) were normalized by that measured after a $500-\mathrm{ms}$ pre-pulse at $-90 \mathrm{mV}$ and plotted as a function of prepulse test potentials (Figure 3D). Coexpression of KCNE3T4A or KCNE3-(WT + T4A) with Kv4.3 + KChIP2b did not significantly modify the steady-state inactivation of $\mathrm{Kv} 4.3+$ KChIP2b + KCNE3 channels (Figure 3D; Table 2).

Because the changes in the time course of reactivation can also affect Ito current, a double-pulse protocol (Figure 4A) was used to test the effect of KCNE3-T4A or KCNE3-(WT+ $\mathrm{T} 4 \mathrm{~A})$ coexpression on the time course for recovery from inactivation. Figures $\mathbf{4 A}, \mathbf{B}$ shows the representative current traces for coexpression of KCNE3-WT and KCNE3-T4A. Figure 4C shows the time courses of recovery of KCNE3-WT, KCNE3$\mathrm{T} 4 \mathrm{~A}$ and $\mathrm{KCNE} 3-(\mathrm{WT}+\mathrm{T} 4 \mathrm{~A})$ coexpression together with
Kv4.3+KChIP2b. Time constants $(\tau)$ of recovery from inactivation are listed in Table 2. Coexpression of KCNE3-T4A or KCNE3-(WT+T4A) did not affect the time course of recovery from inactivation.

\section{Phenotype of KCNE3-T4A Mutation in a Simulated Human Right Ventricular Wall Model}

To clarify whether the gain of function of Ito resulting from KCNE3-T4A mutation is indeed responsible for the Brugadapattern ECG, we performed computer simulations using the 1-D myocardial model of human right ventricular wall. Based on the Ito obtained in electrophysiologic recording (Figures 3A,B,D), we numerically reproduced the current-voltage relationship curves (Figure 5A), the normalized conductance-voltage relationship curves (Figure 5B), and the steadystate inactivation curves (Figure 5C) of the KCNE3-WT and KCNE3-T4A channels. The numerically reproduced Ito was incorporated into the 1-D right ventricular wall model, consisting of endocardial and epicardial layers (Figure 5D). We found that the difference in the phase 2 AP between endocardial and epicardial layers in the KCNE3-T4A model was larger than that in the KCNE3-WT model, and therefore the simulated right precordial ECG showed ST-segment elevation in the case of KCNE3-T4A (Figure 5E).

To examine the adequacy of the KCNE3-T4A model, we additionally conducted simulations with sodium channel blockade. In the case of KCNE3-WT (Figure 5F), because sodium channel block ( $\mathrm{INa}_{\mathrm{Na}} 50 \%$ ) did not increase the difference in phase 

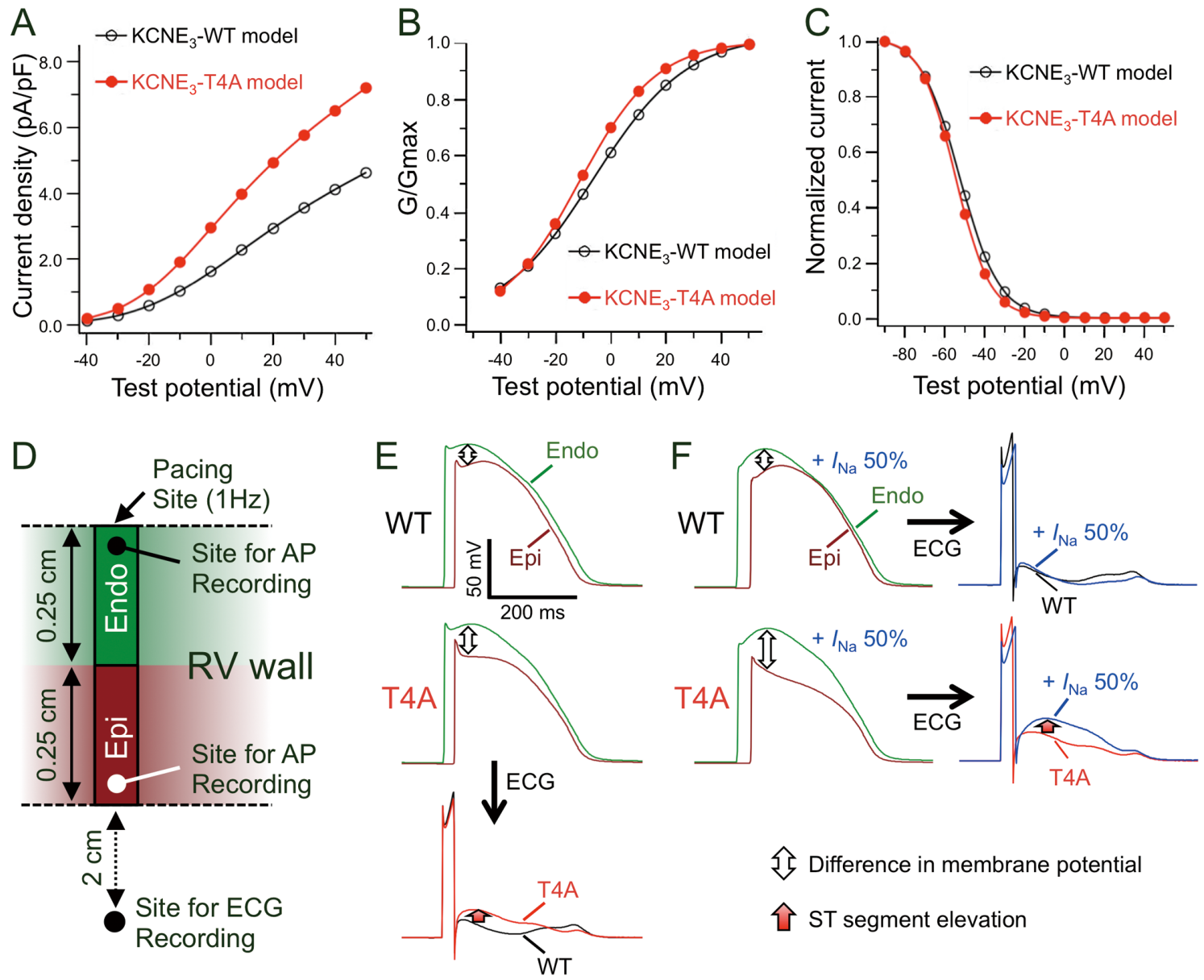

Figure 5. (A-C) Numerically reproduced (A) current-voltage relationship curves, (B) normalized conductance-voltage relationship curves, and (C) steady-state inactivation curves of KCNE3-WT and KCNE3-T4A models. (D) One-dimensional bidomain myocardial computer model, representing the electrical behaviors of the right ventricular wall. The sites for pacing and recording action potential (AP) and electrocardiogram (ECG) are shown. (E) Influence of KCNE3-T4A mutation on both AP and ECG. Endo, endocardial layer; Epi, epicardial layer. (F) Effect of sodium channel blockade (INa 50\%) on both AP and ECG in KCNE3-WT and KCNE3-T4A cases.

1 AP between endocardial and epicardial layers, no ST-segment elevation was observed in the simulated ECG. In contrast, in the case of KCNE3-T4A (Figure 5F), the same sodium channel block caused the loss of dome of AP in the epicardial layer rather than the endocardial layer, and therefore the simulated ECG showed marked ST-segment elevation, consistent with clinical observation (Figure 1C).

\section{Discussion}

We identified a KCNE3 T4A mutation among 40 consecutive patients with Brugada-pattern ECG. The index patient had experienced several episodes of syncope, possibly due to NMS rather than BrS-related ventricular tachyarrhythmias.

The gain of function of Ito by mutations in genes that encode Ito had been thought to cause BrS. ${ }^{14,15}$ Indeed, an R99H mutation in $K C N E 3$ was recently identified in $1 \mathrm{BrS}$ family. ${ }^{6}$ Functional analysis of Ito reconstituted by Kv4.3/KCNE3-R99H showed a gain of function of the channel with a dominantpositive effect. Moreover, the mutation was co-segregated with ECG phenotype. ${ }^{6}$ Therefore, the mutation underlies the development of BrS. KCNE3 T4A, the variant identified in the present cohort, could be a candidate for another KCNE3 mutation that is associated with $\mathrm{BrS}$.

We reconstituted Ito by coexpressing Kv4.3 with KCNE3+ $\mathrm{KChIP} 2 \mathrm{~b}$ in $\mathrm{CHO}$ cells, and examined the functional consequence of KCNE3-T4A, because KChIP2 associates with Kv4 and increases $\mathrm{Kv} 4$ current with the increase of surface expression of $\mathrm{Kv} 4$, by facilitating the trafficking of the channel and the kinetic changes that more resemble native Ito. ${ }^{35} \mathrm{KCNE} 3-$ T4A also increased Ito with a dominant-positive effect. Moreover, computer simulations based on the Ito obtained in electrophysiological recordings demonstrated that KCNE3-T4A recapitulated the ECG phenotype in the present case. These results indicate that $K C N E 3 \mathrm{~T} 4 \mathrm{~A}$ could underlie the pathogenesis of Brugada-pattern ECG. Although it may be required to demonstrate a co-segregation of $K C N E 3$ T4A with ECG phenotype to validate that the $K C N E 3 \mathrm{~T} 4 \mathrm{~A}$ is associated with Brugada-pattern ECG, we unfortunately could not investigate the patient's family members because of lack of consent. 
The precise molecular mechanisms of the reverse of KCNE3induced suppression of Kv4.3 by KCNE3-T4A remain to be elucidated. Delpón et al demonstrated, using coimmunoprecipitation techniques, that KCNE3 coassociates with Kv4.3 in human atrial myocardium and rat ventricular myocardium. ${ }^{6}$ In addition, Lundby and Olesen reported that KCNE3 has an inhibitory effect on $\mathrm{Kv} 4.3$ independent of the presence of KChIP2 in a heterologous expression system. ${ }^{20}$ Therefore, although we recapitulated Ito in the presence of KChIP2b, KCNE3-T4A might reverse the KCNE3-induced suppression of $\mathrm{Kv} 4.3$ in the absence of KChIP2b, as is the case with KCNE3-R99H reported by Delpón et al. ${ }^{6}$ Interestingly, Lundby and Olesen also reported that delayed injection of KCNE3 into Xenopus oocytes can almost completely inhibit Kv4.3 current, suggesting that KCNE3 transcription can act as a regulatory mechanism of the Kv4.3 current density. ${ }^{20}$ Further studies of the transcription, trafficking and turnover rate of K4.3 channel and channel complexes in the presence or absence of KChIP2b and KCNE3-WT/T4A, would be required to elucidate the mechanisms of the reverse of KCNE3-induced suppression of Ito by KCNE3-T4A.

Yokokawa et al reported that $35 \%$ of patients with Brugadapattern ECG had positive responses during the HUT test, ${ }^{30}$ demonstrating a high prevalence of NMS among individuals with Brugada-pattern ECG. Although the autonomic nervous system may play an important role in the development of both $\mathrm{BrS}$ and NMS, the precise pathophysiological link between $\mathrm{BrS}$ and NMS remains to be elucidated. The identification of a novel SCN5A Q55X mutation in a patient with Brugada-pattern ECG presenting as NMS and the expression of SCN5A in both myocardial cells and intracardiac ganglia raise the possibility of a genetic association between $\mathrm{BrS}$ and NMS. ${ }^{36,37}$ $K C N E 3$ (MiRP2) is also expressed in not only the heart but also the central nervous system, and it modulates delayed rectifier currents in mammalian neurons by forming native channel complexes with Kv2.1 and Kv3.1b. ${ }^{38}$ Taken together, $K C N E 3$ T4A may be associated with both phenotypes of $\mathrm{BrS}$ and NMS.

In contrast, we have previously reported that $K C N E 3$ mutations (R99H and T4A) are associated with long QT syndrome (LQTS). ${ }^{39}$ A functional analysis of KCNQ1 + KCNE3-R99H coexpression demonstrated a reduction of the repolarizing potassium current, thus supporting the proposition that $K C N E 3$ $\mathrm{R} 99 \mathrm{H}$ could be a cause of LQTS. A functional analysis of KCNQ1 + KCNE3-T4A, however, could not demonstrate significant functional abnormalities. Regarding the present case, the QTc interval was not prolonged. Therefore, further studies would be necessary to establish the association between $K C N E 3$ T4A and LQTS. Along with this line, 2 KCNE3 T4A carriers we previously reported had no apparent spontaneous ST-segment elevation in the right precordial ECG leads. ${ }^{39}$ One carrier was a 16-year-old boy, much younger than most affected patients, and another was an old woman. Pharmacological provocation tests were not performed to study whether they had Brugada-pattern ECG.

\section{Conclusions}

We identified a $K C N E 3$ T4A mutation in a Japanese patient with Brugada-pattern ECG presenting as NMS. Its functional consequence was the gain of function of Ito, which could underlie the pathogenesis of Brugada-pattern ECG. The data provide novel insight into the genetic basis of Japanese $\mathrm{BrS}$. Further studies are required to clarify whether the $K C N E 3$ T4A mutation is also associated with NMS and/or LQTS.

\section{Acknowledgments}

We thank the patients for their participation in this study. We thank Takako Kobayashi and Yukiyo Tosaka for helping with the genetic analysis. This work was supported, in part, by a Grant-in-Aid for Scientific Research from the Ministry of Education, Culture, Sports, Science and Technology (to T.N. and M.H.). This work was also supported by grants from the Uehara Memorial Foundation and the Ministry of Health, Labor and Welfare of Japan for Clinical Research on Measures for Intractable Diseases (to M.H.), and the National Natural Science Foundation of China (\#81273501 to J.W. and W.G.D.).

\section{Disclosures}

Conflict of interest to declare: None.

\section{References}

1. Chen Q, Kirsch GE, Zhang D, Brugada R, Brugada J, Brugada P, et al. Genetic basis and molecular mechanism for idiopathic ventricular fibrillation. Nature 1998; 392: 293-296.

2. London B, Michalec M, Mehdi H, Zhu X, Kerchner L, Sanyal S, et al. Mutation in glycerol-3-phosphate dehydrogenase 1 like gene (GPD1L) decreases cardiac $\mathrm{Na}+$ current and causes inherited arrhythmias. Circulation 2007; 116: 2260-2268.

3. Van Norstrand DW, Valdivia CR, Tester DJ, Ueda K, London B, Makielski JC, et al. Molecular and functional characterization of novel glycerol-3-phosphate dehydrogenase 1 like gene (GPD1-L) mutations in sudden infant death syndrome. Circulation 2007; 116: 2253-2259.

4. Antzelevitch C, Pollevick GD, Cordeiro JM, Casis O, Sanguinetti MC, Aizawa Y, et al. Loss-of-function mutations in the cardiac calcium channel underlie a new clinical entity characterized by ST-segment elevation, short QT intervals, and sudden cardiac death. Circulation 2007; 115: 442-449.

5. Watanabe H, Koopmann TT, Le Scouarnec S, Yang T, Ingram CR, Schott JJ, et al. Sodium channel betal subunit mutations associated with Brugada syndrome and cardiac conduction disease in humans. J Clin Invest 2008; 118: 2260-2268.

6. Delpón E, Cordeiro JM, Núñez L, Thomsen PE, Guerchicoff A, Pollevick GD, et al. Functional effects of KCNE3 mutation and its role in the development of Brugada syndrome. Circ Arrhythm Electrophysiol 2008; 1: 209-218.

7. Hu D, Barajas-Martinez H, Burashnikov E, Springer M, Wu Y, Varro A, et al. A mutation in the beta 3 subunit of the cardiac sodium channel associated with Brugada ECG phenotype. Circ Cardiovasc Genet 2009; 2: 270-278.

8. Kattygnarath D, Maugenre S, Neyroud N, Balse E, Ichai C, Denjoy I, et al. MOG1: A new susceptibility gene for Brugada syndrome. Circ Cardiovasc Genet 2011; 4: 261-268.

9. Giudicessi JR, Ye D, Tester DJ, Crotti L, Mugione A, Nesterenko VV, et al. Transient outward current (I(to)) gain-of-function mutations in the KCND3-encoded Kv4.3 potassium channel and Brugada syndrome. Heart Rhythm 2011; 8: 1024-1032.

10. Ohno S, Zankov DP, Ding WG, Itoh H, Makiyama T, Doi T, et al. KCNE5 (KCNE1L) variants are novel modulators of Brugada syndrome and idiopathic ventricular fibrillation. Circ Arrhythm Electrophysiol 2011; 4: 352-361.

11. Barajas-Martinez H, Hu D, Ferrer T, Onetti CG, Wu Y, Burashnikov $\mathrm{E}$, et al. Molecular genetic and functional association of Brugada and early repolarization syndromes with S422L missense mutation in KCNJ8. Heart Rhythm 2012; 9: 548-555.

12. Antzelevitch C. Genetic, molecular and cellular mechanisms underlying the J wave syndromes. Circ J 2012; 76: 1054-1065.

13. Nabauer M, Beuckelmann DJ, Uberfuhr P, Steinbeck G. Regional differences in current density and rate-dependent properties of the transient outward current in subepicardial and subendocardial myocytes of human left ventricle. Circulation 1996; 93: 168-177.

14. Yan GX, Antzelevitch C. Cellular basis for the Brugada syndrome and other mechanisms of arrhythmogenesis associated with ST-segment elevation. Circulation 1999; 100: 1660-1666.

15. Antzelevitch C. Brugada syndrome. Pacing Clin Electrophysiol 2006; 29: $1130-1159$.

16. Dixon JE, Shi W, Wang HS, McDonald C, Yu H, Wymore RS, et al. Role of the Kv4.3 K+ channel in ventricular muscle: A molecular correlate for the transient outward current. Circ Res 1996; 79: 659668 .

17. Kuo HC, Cheng CF, Clark RB, Lin JJ, Lin JL, Hoshijima M, et al. A defect in the Kv channel-interacting protein 2 (KChIP2) gene leads to a complete loss of I(to) and confers susceptibility to ventricular tachycardia. Cell 2001; 107: $801-813$. 
18. Decher N, Uyguner O, Scherer CR, Karaman B, Yuksel-Apak M, Busch AE, et al. hKChIP2 is a functional modifier of hKv4.3 potassium channels: Cloning and expression of a short hKChIP2 splice variant. Cardiovasc Res 2001; 52: 255-264.

19. Radicke S, Cotella D, Graf EM, Banse U, Jost N, Varro A, et al. Functional modulation of the transient outward current Ito by KCNE betasubunits and regional distribution in human non-failing and failing hearts. Cardiovasc Res 2006; 71: 695-703.

20. Lundby A, Olesen SP. KCNE3 is an inhibitory subunit of the Kv4.3 potassium channel. Biochem Biophys Res Commun 2006; 346: 958 967.

21. Radicke S, Cotella D, Graf EM, Ravens U, Wettwer E. Expression and function of dipeptidyl-aminopeptidase-like protein 6 as a putative beta-subunit of human cardiac transient outward current encoded by Kv4.3. J Physiol 2005; 565: 751-756.

22. Aimond F, Kwak SP, Rhodes KJ, Nerbonne JM. Accessory Kvbeta1 subunits differentially modulate the functional expression of voltagegated $\mathrm{K}+$ channels in mouse ventricular myocytes. Circ Res 2005; 96: $451-458$.

23. Niwa N, Nerbonne JM. Molecular determinants of cardiac transient outward potassium current (I(to)) expression and regulation. $J$ Mol Cell Cardiol 2010; 48: 12-25.

24. Wu J, Shimizu W, Ding WG, Ohno S, Toyoda F, Itoh H, et al. KCNE2 modulation of Kv4.3 current and its potential role in fatal rhythm disorders. Heart Rhythm 2010; 7: 199-205.

25. Nakajima T, Kaneko Y, Saito A, Irie T, Tange S, Iso T, et al. Identification of six novel SCN5A mutations in Japanese patients with Brugada syndrome. Int Heart J 2011; 52: 27-31.

26. Ogawa R, Kishi R, Takagi A, Sakaue I, Takahashi H, Matsumoto N, et al. A novel microsatellite polymorphism of sodium channel beta1subunit gene (SCN1B) may underlie abnormal cardiac excitation manifested by coved-type ST-elevation compatible with Brugada syndrome in Japanese. Int J Clin Pharmacol Ther 2010; 48: 109-119.

27. Makiyama T, Akao M, Haruna Y, Tsuji K, Doi T, Ohno S, et al. Mutation analysis of the glycerol-3 phosphate dehydrogenase-1 like (GPD1L) gene in Japanese patients with Brugada syndrome. Circ J 2008; 72: $1705-1706$.

28. Shimizu A. Is this a philosophic issue? Do patients with drug-induced Brugada type ECG have poor prognosis? (Pro) Circ J 2010; 74: 24552463.
29. Nishizaki M, Sakurada H, Yamawake N, Ueda-Tatsumoto A, Hiraoka M. Low risk for arrhythmic events in asymptomatic patients with drug-induced type 1 ECG. Do patients with drug-induced Brugada type ECG have poor prognosis? (Con) Circ J 2010; 74: 2464-2473.

30. Yokokawa M, Okamura H, Noda T, Satomi K, Suyama K, Kurita T, et al. Neurally mediated syncope as a cause of syncope in patients with Brugada electrocardiogram. J Cardiovasc Electrophysiol 2010; 21: $186-192$.

31. Nakajima T, Kaneko Y, Irie T, Takahashi R, Kato T, Iijima T, et al. Compound and digenic heterozygosity in desmosome genes as a cause of arrhythmogenic right ventricular cardiomyopathy in Japanese patients. Circ J 2012; 76: 737-743.

32. Priebe L, Beuckelmann DJ. Simulation study of cellular electric properties in heart failure. Circ Res 1998; 82: 1206-1223.

33. Tsuji-Wakisaka K, Akao M, Ishii TM, Ashihara T, Makiyama T, Ohno $\mathrm{S}$, et al. Identification and functional characterization of KCNQ1 mutations around the exon 7-intron 7 junction affecting the splicing process. Biochim Biophys Acta 2011; 1812: 1452-1459.

34. Wang S, Bondarenko VE, Qu Y, Morales MJ, Rasmusson RL, Strauss HC. Activation properties of Kv4.3 channels: Time, voltage and [K+]o dependence. J Physiol 2004; 557: 705-717.

35. An WF, Bowlby MR, Betty M, Cao J, Ling HP, Mendoza G, et al. Modulation of A-type potassium channels by a family of calcium sensors. Nature 2000; 403: 553-556.

36. Makita N, Sumitomo N, Watanabe I, Tsutsui H. Novel SCN5A mutation (Q55X) associated with age-dependent expression of Brugada syndrome presenting as neurally mediated syncope. Heart Rhythm 2007; 4: 516-519.

37. Scornik FS, Desai M, Brugada R, Guerchicoff A, Pollevick GD, Antzelevitch C, et al. Functional expression of "cardiac-type" Nav1.5 sodium channel in canine intracardiac ganglia. Heart Rhythm 2006; 3: $842-850$.

38. McCrossan ZA, Lewis A, Panaghie G, Jordan PN, Christini DJ, Lerner DJ, et al. MinK-related peptide 2 modulates Kv2.1 and Kv3.1 potassium channels in mammalian brain. $J$ Neurosci 2003; 23: $8077-$ 8091.

39. Ohno S, Toyoda F, Zankov DP, Yoshida H, Makiyama T, Tsuji K, et al. Novel KCNE3 mutation reduces repolarizing potassium current and associated with long QT syndrome. Hum Mutat 2009; 30: 557 563. 